\title{
O PERFIL DO AGRESSOR SEXUAL INFANTIL: UMA REVISÃO BIBLIOGRÁFICA
}

\section{Child sex profile profile: a bibliographic review}

\author{
Alaniane Souza Freire Santos - Centro Universitário Maurício de Nassau /Brasil \\ Ana Catarina Correia Mesquita - Centro Universitário Maurício de Nassau /Brasil
}

\begin{abstract}
RESUMO: Este artigo diz respeito a uma revisão bibliográfica acerca do perfil psicológico do agressor sexual infantil, sobre as influencias negligentes ambientais, fatores familiares e culturais que na infância desperta o ser ao ato futuro de ofensa sexual como busca de alívio e prazer. Objetivo: Nesta análise, procurou-se entender a sua construção biopsicossocial desde a infância até a prática da violência. Métodos: por meio de discussão de literatura dos materiais aqui citados retirados de plataformas pontuadas no decorrer deste estudo. Resultados: através das apresentações de diversos olhares de estudiosos acerca do violento sexual contra crianças, analisando até mesmo o seu pensamento sobre a vítima, entendendo também que o ato ocorre em diversas classes sociais. Conclusão: Muitos estudos investigam a vítima, poucos estudam o agressor sexual infantil, neste contexto está a importância de averiguar a formação do perfil psicológico do ofendedor, pois esta área ainda é carente de estudo.
\end{abstract}

Palavras-chave: Abuso infantil. Agressor sexual infantil. Perfil do agressor.

ABSTRACT: This article is about a bibliographical review about the psychological profile of the child sexual aggressor, about the negligent environmental influences, family and cultural factors that awakens being to the future act of sexual offense as a search for relief and pleasure. Objective: In this analysis, we sought to understand its biopsychosocial construction from childhood to the practice of violence. Methods: by discussing the literature of the materials cited here taken from punctuated platforms during this study. Results: through the presentation of diverse perspectives of scholars about sexual violence against children, analyzing even their thinking about the victim, also understanding that the act occurs in various social classes. Conclusion: Many studies investigate the victim, few study the child sex offender, in this context is the importance of ascertaining the formation of the psychological profile of the offender, as this area is still lacking in study.

Keywords: Child Abuse. Child sex offender. Profile of the aggressor.

\section{INTRODUÇÃO}

O pensamento formulado por Michaud (1989) retrata a agressão como um acontecimento que, muitos sujeitos através de relação direta ou indireta com o próximo, provoca perdas machucando não somente em sua dignidade corpórea e moral, como também riquezas, costumes, crenças, comportamentos e compreensão.

Educação, Psicologia e Interfaces, Volume 3, Número 2, p. 85-100, Maio/Agosto, 2019. ISSN: 2594-5343. DOI: 
Segundo Gomes et al. (2002) é comprovado que a cada ano cresce em nosso país a agressão contra crianças e jovens, se constituindo num grave problema de saúde pública, inclusive nos anos 60 os delitos sexuais a criminologia refletia pouca atenção. Entretanto, depois disto, essa temática foi ponto de pesquisa da psicologia e da psiquiatria, tendo sido efetuados várias pesquisas na tentativa de entender essa problemática (BLACKBURN,1993). Mas, há lacuna no que diz respeito a pesquisas sobre os agressores, visto que a maior parte deleas tem como foco as vítimas de ofensa sexual (MOURA, 2007).

A carência de análises sobre os agressores, demonstrado a relevância de se desenrolar conceitos sobre o que leva os ofendedores a cometer tais atos, qual o seu perfil e incitação. Relevante compreender os arcabouços conceituais para as intervenções com os ofendedores, em um aspecto de precaução e tratamento, pois não se pode agir sem ter conhecimento dos aspectos essenciais onde intervir (WARD; BEECH, 2006).

Logo, recomenda-se nesta pesquisa o entendimento dos agressores violentos sexuais no meio da psicologia social. Esta abordagem entende que a compreensão dos elos constitutivos que o indivíduo forma no decorrer da sua trajetória são relevantes, pois não é a existência de uma característica inata, uma inclinação biológica que define a pessoa que comete o delito (CAMINO; ISMAEL, 2004; GUARESCHI et al. 2006). Portanto, o objetivo deste artigo é descrever o que impulsiona o ofendedor a prática de agressão sexual infantil, considerando o seu perfil psicológico e o seu sentimento em relação a ofensa sexual infantil, para isso realizou uma pesquisa de revisão bibliográfica.

Para realização desse estudo bibliográfico organizou-se esquemas dos materias lidos sobre o tema ofendedores sexuais infantis. Para Sampaio e Mancini (2007) as conclusões presentes ou em estudos de determinado tema são mais robustas quando se consegue demonstrar que diferentes estudos investigam as mesmas características e fornecem dados que suportam constatações semelhantes.

Para efetuar este trabalho, foi realizado uma pesquisa nos bancos de dados do Google acadêmico, Literatura Latino-Americana e do Caribe em Ciências da Saúde (LILACS), periódicos eletrônicos em psicologia (PEPSIC), visto que são meios que disponibilizam pesquisas realizadas com diferentes enfoques teóricos e metodológicos. Os relatores em português aplicados para a catalogação foram: Agressor sexual, ofendedor sexual, estuprador, abusador, violentador e insultador. Foram realizadas 15

Educação, Psicologia e Interfaces, Volume 3, Número 3, p. 85-100, Maio/Agosto, 2019. 
buscas, identificados 37 artigos, dos quais 22 foram descartados. Ao final, foram 15 artigos selecionados com base nos critérios, não havendo títulos repetidos apresentados a seguir.

Os critérios de inclusão foram: artigos de base de dados do Googlo acadêmico, LILACS, PEPSIC publicados entre os anos de 2013 até 2019, como também os trabalhos de conclusão de curso, tese e dissertações em psicologia que abrange o tema pesquisado e no idioma português. Enquanto os critérios de exclusão foram: materiais que abordassem apenas a pedofilia, abuso de mulheres, abuso de idosos e adolescentes e que relatassem, apenas, sobre o ofendido.

Quanto ao procedimento e a coleta de dados, a procura dos materiais para este estudo começou em 18 de setembro de 2018 à 18 de abril de 2019, partindo de uma procura organizada, a revisão bibliográfica foi feita em ordem sequencial, em que os artigos foram organizados em pastas.

\section{INVESTIGAÇÃO DOS TRAÇOS DA PERSONALIDADE DO AGRESSOR}

Nos estudos de Allard-Dansereau et al. (1997), Brewster et al. (1998), Craissatti e McClurg (1997) observou-se que, atualmente, existe criação compacta, ampla e diferenciada sob a condição biopsicossocial dos ofendedores sexuais infantil. No Brasil a criação técnica sobre os transgressores sexuais de crianças e jovens ainda é iniciante quando igualada a quantidade de pesquisas em contexto mundial e cabe pontuar que dos elementos que influência a sexualidade humana é a cultural, abarcando os padrões de vontades, atitudes e ideias sexuais criados nas variadas sociedades e grupos sociais (TELES,1999), a experiência de uma sexualidade conforme os padrões esperados pela sociedade deve levar em conta esse aspecto.

Contudo, é notável que há vivências da sexualidade que fogem dos padrões sociais esperados se constituindo como delitos e violência, assim é relevante distinguir abuso sexual de pedofilia. $\mathrm{O}$ abuso sexual diz respeito a um comportamento marcado pela inevitável vontade de praticar o poder sobre a criança, já a pedofilia é vista como um transtorno sexual, uma parafilia, e como tal conceituada por protótipos de fetiches e ações sexuais exageradas e constantes envolvendo crianças, o que traz consequência maléfica para o sujeito e dano potente para outros indivíduos. O pedófilo não experiência desejo

Educação, Psicologia e Interfaces, Volume 3, Número 2, p. 85-100, Maio/Agosto, 2019. ISSN: 2594-5343. DOI: 
sexual por pessoas da mesma idade, mas por gênero infantil impúberes (DALGALARRANDO, 2008).

De acordo com Araújo (2004), a violência sexual de crianças é marcada pela exposição infantil a exibições sexuais inadequadas para a sua idade, em que a pessoa madura ou juvenil mais amadurecida propõe ao sofredor com a sua vontade ou não, a realizar prazer ou estimular suas vontades eróticos, requerendo pela força corporal, constrangimento, encantando com palavras e oferecendo objetos de agrado.

A agressão sexual contra gênero infanto-juvenil, tornou-se uma questão de saúde pública na década de 1980 (FERRARI, VACINA, 2002), e a partir deste marco, várias análises de conhecimento têm tido como apreciação, principalmente, o pagante ou os responsáveis que não praticaram a impetuosidade. Nestas análises, os praticantes de violência sexual habitualmente têm sido descuidados (AZEVEDO, GUERRA,1988; FALEIROS, 2003; HABIGZANG et al. 2005).

Ao averiguar e compreender o comportamento libidinoso afrontoso, estudos tem tem sinalizado sobre a atuação e os sinais da personalidade de causadores da ação abusiva sexual (PRENTKY, KNIGHT; LEE, 2008). O assunto traz, ademais, uma rancidez histórica e sociável dos inúmeros prejulgamentos que frisou a análise sociológica, antropológica, psicológica, entre outras repartições da compreensão (MORAIS et al. 2007; MOURA, 2007).

Mohr, Turner e Jerry (1964 apud QUINSEY; LALUMIÈRE, 2001) realizaram uma averiguação arquetípica na década de 60 na qual qualificaram 55 agressores sexuais de crianças supramencionado pelos tribunais. Os autores perceberam que os violentadores sexuais infantis dificilmente tinham transtornos psicóticos e não eram menos intelectuais e nem menos alfabetizados que os cidadãos da totalidade. Meloy, Gacono e Kenney (1994), estudando assassinos sexuais, perceberam o aparecimento de irritação constante, sentimentos nulos e ideias fixas. As afeições são costumeiras ligadas a importantes refreamentos no apoio de suas demandas sentimentais, à reflexão intima indisposição e à desordem da ideia fixa. Contudo, Para Cohen e Gobbetti (2002 apud MARQUES, 2005), os sujeitos que realizam a agressão sexual apresentam desordem de categoria integra, grupal e psicológica, fazendo-se indignos para compreender as demonstrações, emoções e as reflexões do próximo, tornando-se então como indivíduos inertes de recurso terapêutico. Salter (2009) relata que certas análises designam o ponto ao nível maior de

Educação, Psicologia e Interfaces, Volume 3, Número 3, p. 85-100, Maio/Agosto, 2019. ISSN: 2594-5343. DOI: 
hormônios do homem androgênicos, que suportariam a violência. Classificar tais traços é um difícil obstáculo, prioritariamente no âmbito do Brasil, de modo que são deficientes as tarefas e os meios de exames de transtornos do ego (CARVALHO, BARTHOLOMEU, SILVA, 2010).

O Manual Diagnóstico de Transtornos Mentais (DSM-5), considera a parafilia como “[...] algum empenho sexual vivo e constante que não aquele tornado para a excitação genital ou carinhos preliminares com companheiros afetuosos que admitem e ofereçam fenótipo natural e amadurecimento corporal [...]" (AMERICAN PSYCHIATRIC ASSOCIATION, 2014, p.665), no entanto, a análise de Miler trazido por Jesus (2006), destaca que pelo menos uma criança dentre oito que sofrem agressão sexual, transformam-se em abusadores quando crescido. Neste sentido, é importante distinguir violência sexual de pedofilia para não se considerar como tal, algum obra avulso de abuso sexual (FAGAN et al. 2002 apud BARLOW; DURAN, 2008), pois, o sujeito que sofre desordem pedofílica alarga uma mitomania, isso significa que, uma ampla competência em mentir, envolvendo, persuadindo e difundindo a criança de feitio fascinante e afetuoso, o que colabora para que $90 \%$ dos acontecimentos não sejam desvendados e acabem por alongados períodos em andamento, ao passo que para o agressor sexual não faz uso dessas astúcias, aproveitando ao passo que o ofendedor sexual usando muitas vezes de brutalidade corporal para com a vítima, que pode ser uma criança, com vistas à sua satisfação sexual (ORLANDELI; GRECCO, 2012).

\section{A NOÇÃO DO OUTRO PARA O AGRESSOR}

A escolha sexual de um afrontoso sexual pode ser mensurada pelas medidas falométricas, tal como o pletismógrafo peniano, que define a fisionomia ocasional de um coletivo de incentivos audiovisuais, realizado por motivações sexualmente divergente e incitamento sexualmente normais (imparcial) (CHAPLIN, RICE, HARRIS, 1995 apud CARVALHO, 2011). Ressaltando sobre isso, Padilha e Gomide (2004) afirmam que a construção do arcabouço psicopatológico do agressor sexual se desencadeia geralmente diante de experiências de sofrimento na infância.

No entanto, Marshall (2001), aponta que adolescentes abusadores sexuais não necessariamente foram abusados sexualmente, embora esse seja um fator formidável no desenvolvimento da conduta agressiva. Mas esse autor compreende que outros aspectos

Educação, Psicologia e Interfaces, Volume 3, Número 2, p. 85-100, Maio/Agosto, 2019. ISSN: 2594-5343. DOI: 
concorrem para o cometimento de atos ofensivos, como: experiências de maltrato físico na infância; ambiente familiar agressivo, contundente e transgressor que propicia um relacionamento destrutivo entre pais e filhos; experiências emocionais que desenvolvem baixa autoestima no adolescente; bem como falta de acolhimento afetivo familiar. Essas características do relacionamento familiar desenvolvem no adolescente, fantasias de dominação e força sobre o outro, como forma de enfrentamento de relações sociais e afetivas, e estratégias de "solução" de problemas. Segundo Geneviève e Tardif (2014) os défices de intimidade nos agressores sexuais são percebidos como dificuldades interpessoais, estando na origem da ansiedade social e do medo de intimidade, juntamente aos sentimentos de insatisfação nas relações e à incapacidade de alterar este padrão, provocam sentimentos de solidão que motivam estes agressores a procurar formas alternativas de satisfação na intimidade.

Na perspectiva Sociocultural há uma predisposição para alguns desempenhos sexuais e inibição para outros (VIEIRA, 2011). Deste modo, a agressão sexual torna-se apreendida pelas influências culturais, apreendidas sob determinadas atitudes, estereótipos sexuais e aprendizagem da socialização masculina face à agressão física e ao ato sexual (MARIA, 2004 apud BALAIAS et. al. 2012). Vale ressaltar que um dos aspectos constituintes da sexualidade humana é a dimensão cultural, que se refere aos padrões de desejos, comportamentos e fantasias sexuais criados pelas diversas sociedades e grupos sociais. A vivência de uma sexualidade "normal" deve considerar esse aspecto (TELES, 1999). A análise confirma ainda o posicionamento teórico de Sanderson (2005), bem como pontua a precisão de uma imprescindível desmistificação sobre as pessoas que cometem violência sexual contra crianças e adolescentes. Existe uma menor probabilidade de o agressor ser psicopata quando a vítima é um elemento da família, do que quando a vítima não é da família do agressor. Portanto existe uma maior probabilidade de haver psicopatas em agressores extrafamiliares do que intrafamiliares (VIEIRA, 2010).

Abusadores sexuais de menores extrafamiliares têm défices de competências de relacionamento íntimo, a solidão também aparece de forma significativa nos ofensores sexuais (SEIDMAN et al. 1994). Esses indivíduos não são, em grande parte, estranhos, nem loucos, e nem podem ser reconhecidos por atributos físicas, como se acredita. Eles provêm de todos os tipos de classes sociais, grupos étnicos e faixas etárias. O conceito de

Educação, Psicologia e Interfaces, Volume 3, Número 3, p. 85-100, Maio/Agosto, 2019. 
"monstro" cria uma demonização dos abusadores, e passa-se a tratá-los como doentes e maus, enquanto os que não violentam seriam sadios e bons.

$\mathrm{Na}$ presença de distorções cognitivas, os indivíduos podem então tornar-se incapazes de interpretar as situações interpessoais e de compreender as outras pessoas, e essa incapacidade para inferir com precisão crenças, desejos, emoções, intenções e necessidades dos outros dificulta o estabelecimento de uma relação empática com os outros e a resolução eficaz dos conflitos relacionais (GOPNIK, MELTZOFF, 1997). Contudo, a grande vantagem do modelo reside no fato de incluir variáveis para além das distorções cognitivas, como sendo as predisposições do próprio sujeito, as suas experiências, a falta de empatia e de autocontrole, indo de encontro à ideia de que o ato da ofensa sexual não é determinado por apenas um fator, mas sim pela integração de vários (THAKKER, WARD, 2012; WARD, BEECH, 2006). Contrariando a afirmativa, Burn e Brown (2006, p. 231), ao contradizem a conjectura dos déficits de empatia, de tal modo se posicionam:

Se os ofendedores sexuais infantis são meditados como deficientes em sentimentos, então a violência ficaria instigada pela precisão de domínio e autoridade; o cometimento sexual do ofensor deve ser saciado, independente das emoções de suas vítimas. Apesar disso, não se trata diste, pois, diversos abusadores de crianças sentem-se atraídos emocionalmente por uma criança e são capazes de manipular e atrair suas vítimas. Isto possivelmente mostra uma consciência sensitiva dos sentimentos e crenças das crianças.

Apesar de saberem que estão a agir mal, convencem-se de que o seu comportamento é aceitável (KOCSIS, COOKSEY, IRWIN, 2002) e que a criança quer relacionar-se sexualmente com ele, projetando nela os pensamentos e sentimentos que ele quer que ela tenha sobre ele e de que seu comportamento abusivo não causa estragos nem é prejudicial para a criança (LANNING, 1991). Existem, no entanto, alguns ofensores que não aparentam dificuldades na avaliação do estado mental das vítimas, muito pelo contrário, são precisos e revelam uma extraordinária capacidade em ler as outras pessoas, os seus sentimentos, crenças e expetativas, utilizando isso em seu proveito, manipulandoas para alcançarem o que pretendem, revelando uma representação de psicopatia (WARD et al. 2000).

\section{PESQUISAS SOBRE O PERFIL DO AGRESSOR SEXUAL INFANTIL}

Educação, Psicologia e Interfaces, Volume 3, Número 2, p. 85-100, Maio/Agosto, 2019. ISSN: 2594-5343. DOI: 
Visando obter resultados, foram empregados 15 estudos e/ou averiguação tendo como embasamento artigos entre outras formas. Baseando-se nos alicerces de dados SCIELO, LILACS e PEPSIC, onde foi aproveitado pontos admiráveis que colaboraram para a efetivação deste trabalho. Posteriormente a leitura esmiuçadora acerca do assunto escolhido, foram classificados os conhecimentos relatados aos artigos designados no quadro a seguir.

Quadro: Acervo elegido de concordata com autor e título, revista e ano de publicação e principais desfechos.

\begin{tabular}{|c|c|}
\hline Autor/ Título e Fonte & Principais desfechos \\
\hline $\begin{array}{l}\text { Jeane Lessinger Borges e } \\
\text { Veranice Tatiane Zingler. } \\
\text { Fatores de risco e de proteção } \\
\text { em adolescentes vítimas de } \\
\text { abuso sexual } \\
\text { Psicologia em estudo, } 2013 .\end{array}$ & $\begin{array}{l}\text { Este artigo diz respeito a uma observação qualitativa que } \\
\text { mirou acomodar os fatores de arrojo e de auxílio em } \\
\text { Acontecimentos de brutalidade sexual na mocidade. } \\
\text { Constituíram para as entrevistas duas garotas adolescentes } \\
\text { vítimas de abuso sexual, de uma localidade Interna do Rio } \\
\text { Grande do Sul. Os subsídios dos encontros foram } \\
\text { avaliados por meio da Apreciação do Teor (Bardin, 1977). }\end{array}$ \\
\hline $\begin{array}{l}\text { Alexandre Martins Valença, } \\
\text { Isabella Nascimento, Antônio e } \\
\text { Gidio Nardi. } \\
\text { Relação entre crimes sexuais e } \\
\text { transtornos mentais e do } \\
\text { desenvolvimento: uma revisão. } \\
\text { Rev Psiq Clin, 2013. } \\
\end{array}$ & $\begin{array}{l}\text { As desordens mentais e do acréscimo mais repetidamente } \\
\text { pertinentes à perpetração de crimes sexuais foram: } \\
\text { esquizofrenia, perturbação bipolar e retardo mental. São } \\
\text { admiráveis a detecça e o terapêutica da morbidade } \\
\text { psiquiátrica dentre agressores sexuais nos preceitos de } \\
\text { saúde e de justiça criminosa, o que pode colaborar para } \\
\text { menor risco de reincidência desse conduta sexual. }\end{array}$ \\
\hline $\begin{array}{l}\text { Camila Cortellete Pereira da } \\
\text { Silva, Daniela Devico Martins } \\
\text { Pinto e Rute Grossi Milani. } \\
\text { Pedofilia, quem a comete? Um } \\
\text { estudo bibliográfico do perfil do } \\
\text { agressor. } \\
\text { Cesumar, } 2013 \text {. }\end{array}$ & $\begin{array}{l}\text { Acredita-se ser imprescindível a estruturação de artifícios } \\
\text { notórias voltadas para tais sujeitos, oferecendo psicoterapia } \\
\text { aos próprios, como meio de abater a sua reincidência, } \\
\text { conscientizando-os dos agravos ocasionados à vítima. }\end{array}$ \\
\hline $\begin{array}{l}\text { Liana Fortunato Costa, Eika } \\
\text { Lôbo Junqueira, Fernanda } \\
\text { Figueiredo Falcomer Meneses e } \\
\text { Lucy Mary Cavalcanti Stroher. } \\
\text { As relações familiares do } \\
\text { adolescente ofensor sexual } \\
\text { Psico-usf-2013 }\end{array}$ & $\begin{array}{l}\text { Uma melhor análise da agressão atual nas afinidades } \\
\text { domésticas desse jovem é essencial, porque uma qualidade } \\
\text { desses jugulados é a falta de agilidade social, e esse feitio } \\
\text { procede de um procedimento pobre de conexão com seus } \\
\text { pais. }\end{array}$ \\
\hline $\begin{array}{l}\text { Daniela Castro dos Reis, Arthur } \\
\text { Aliverti Saltori de Barros e Lília } \\
\text { Iêda Chaves Cavalcante. } \\
\text { Agressor sexual de crianças e } \\
\text { adolescentes: uma discussão } \\
\text { sobre o gênero dos participantes } \\
\text { na literatura }\end{array}$ & $\begin{array}{l}\text { As análises sobre agressão sexual têm deixado lacunas em } \\
\text { vários assuntos, especialmente em esboços relacionados } \\
\text { com a condição biopsicossocial do atacante. }\end{array}$ \\
\hline
\end{tabular}

Educação, Psicologia e Interfaces, Volume 3, Número 3, p. 85-100, Maio/Agosto, 2019. ISSN: 2594-5343. DOI: 


\begin{tabular}{|c|c|}
\hline P sicuivgia cint Ievista, ZU14. & \\
\hline $\begin{array}{l}\text { Silvana Alba Scortegagna e } \\
\text { Deise Matos do Amparo. } \\
\text { Avaliação psicológica de } \\
\text { ofensores sexuais com o método } \\
\text { de Rorschach. } \\
\text { Psicologia em revista, } 2014 \text {. }\end{array}$ & $\begin{array}{l}\text { Os resultados apontam a presença de baixo amor-próprio e } \\
\text { perdas na autoimagem, na adaptação perceptiva e na } \\
\text { avaliação do fato, além de mortificação na competência de } \\
\text { estabelecer junções, de empatia e na permanência das } \\
\text { assimilações. A sensibilidade ao humano e as experiências } \\
\text { de tortura privada adaptaram diferenças nos } \\
\text { acontecimentos discutidos. Os fundamentais encontrados } \\
\text { remetem os atributos psicológicas comumente retratadas na } \\
\text { bibliografia e vivificam a inexistência de um fato } \\
\text { psicológico exclusivo do ofendedor sexual. }\end{array}$ \\
\hline $\begin{array}{l}\text { Ana Maria Franchi Pincolini, } \\
\text { Cláudio Simon Hutz. } \\
\text { Abusadores Sexuais Adultos e } \\
\text { Adolescentes no Sul do Brasil: } \\
\text { Pesquisa em Denúncias e } \\
\text { Sentenças Judiciais. } \\
\text { Temas em psicologia, 2014. }\end{array}$ & $\begin{array}{l}\text { As consequências aconselharam que entre agressores } \\
\text { crescidos prevaleceu a agressão sexual dentro das famílias } \\
\text { contra ofendidos do sexo feminino, sendo os fundamentais } \\
\text { agressores pais e padrastos das vítimas. Entre ofendedores } \\
\text { juvenis houve preponderância da agressão sexual fora da } \\
\text { família versus vítimas do sexo masculino, principalmente } \\
\text { próximos. Estes sequelas aconselham que pode haver } \\
\text { altercações no perfil dos ofendidos e no tipo de abuso } \\
\text { perpetrado por adultos e adolescentes, hipótese que merece } \\
\text { ser testada em estudos futuros. }\end{array}$ \\
\hline $\begin{array}{l}\text { Amailson Sandro de Barros e } \\
\text { Maria de Fátima Quintal de } \\
\text { Freitas } \\
\text { Violência Doméstica contra } \\
\text { Crianças e Adolescentes: } \\
\text { Consequências e Estratégias de } \\
\text { Prevenção com Pais Agressores } \\
\text { Pensando em famílias, 2015. }\end{array}$ & $\begin{array}{l}\text { Partindo da investigação dos conteúdos, surgiram } \\
\text { determinadas classes, onde duas expressadas aqui e serão } \\
\text { debatidas: as decorrências da agressão familiar contra } \\
\text { meninos (a) e jovens e as táticas de intromissão com grupo } \\
\text { de pais ofendedores. }\end{array}$ \\
\hline $\begin{array}{l}\text { Hellen Cordeiro Oliveira, Elzo } \\
\text { Pereira Pinto Junior, Lívia } \\
\text { Teixeira Tavares, Marina Aguiar } \\
\text { Pires Guimarães e Maria Nice } \\
\text { Dutra de Oliveira. } \\
\text { Notificação compulsória de } \\
\text { violência sexual contra crianças } \\
\text { e adolescentes } \\
\text { Arq. Ciênc. Saúde, } 2015 \text {. }\end{array}$ & $\begin{array}{l}\text { Entre os anos estudados, } 2005(29 \%) \text { apresentou maior } \\
\text { assiduidade de notas. O sexo feminino apresentou máximo } \\
\text { identificador de ofendidos }(83,9 \%) \text { e os acontecimentos } \\
\text { aconteceram especialmente entre a idade de } 11 \text { a } 15 \text { anos } \\
(52,5 \%) \text {. Os fundamentais atacantes eram do sexo másculo } \\
(91,8 \%) \text { e indivíduos próximos da família }(59,2 \%) \text {. A } \\
\text { maior parte dos episódios de agressão sobreveio na } \\
\text { residência }(52,5 \%) \text { e } 76,5 \% \text { das acusações foram confiadas } \\
\text { por familiares. }\end{array}$ \\
\hline $\begin{array}{l}\text { Larissa Rossi da Silva. } \\
\text { O lugar do desejo na criança } \\
\text { sexualmente abusada. } \\
\text { Editora Champagnat, } 2015 \text {. }\end{array}$ & $\begin{array}{l}\text { A medida que o "agressor" é percebido como uma pessoa } \\
\text { desenvolvido e, consequentemente, capaz } \\
\text { psicologicamente e biologicamente para cultivar relações } \\
\text { sexuais (BRANDÃO JR., 2008). }\end{array}$ \\
\hline $\begin{array}{l}\text { Lana dos Santos Wolff, Deise } \\
\text { Matos do Amparo, Roberto } \\
\text { Menezes de Oliveira e Jean } \\
\text { Yves Chagnon. } \\
\text { Problemática } \\
\text { identitária em adolescentes } \\
\begin{array}{l}\text { abusadores } \\
\text { contribuições do }\end{array} \\
\begin{array}{l}\text { Escola de Paris. } \\
\text { Avaliação psicológica, } 2016 .\end{array}\end{array}$ & $\begin{array}{l}\text { Este estudo investiga a hipótese narcísica-indenitária de } \\
\text { jovens que fizeram violência sexual. Saindo da conjectura } \\
\text { de que é perante as transposições psíquicos calhados na } \\
\text { juventude e dos problemas do aparelho psíquico em } \\
\text { desempenhar o papel de paraexcitação que pode acontecer } \\
\text { no caminho ao ato impetuoso. }\end{array}$ \\
\hline
\end{tabular}

Educação, Psicologia e Interfaces, Volume 3, Número 2, p. 85-100, Maio/Agosto, 2019. ISSN: 2594-5343. DOI: 


\begin{tabular}{|c|c|}
\hline $\begin{array}{l}\text { Dalcyra Aparecida Silva. } \\
\text { O olhar do agressor sexual sobre } \\
\text { o abuso sexual infantil. } \\
\text { Centro Universitário católico de } \\
\text { vitória, } 2016 .\end{array}$ & $\begin{array}{l}\text { A agressão é pertinente ao manejo da energia corporal, } \\
\text { enquanto que a violência sexual está catalogada ao } \\
\text { desmoralização e desgoverno das investidas sexuais. Deste } \\
\text { jeito, os perfis de violência sexual são objetivados como } \\
\text { não-agressão. A despeito disso, os atacantes sexuais } \\
\text { entendem como desonesto e depravado o crime que } \\
\text { cometeram, e para fugir do prejuízo direcionado aos } \\
\text { criadores de agressão sexual contra crianças, preferem em } \\
\text { sua maior parte em não admitir A ação incumbida. }\end{array}$ \\
\hline $\begin{array}{l}\text { Juliane Magda Casarin, } \\
\text { Elizabeth Hertel Lenhardt } \\
\text { Botelho, Rosangela Kátia } \\
\text { Sanches Mazzorana Ribeiro. } \\
\text { Ofensores sexuais avaliados pelo } \\
\text { Desenho da Figura Humana. } \\
\text { Avaliação psicológica, 2016. }\end{array}$ & $\begin{array}{l}\text { Os efeitos dessa manifestação mostram indícios de } \\
\text { problemas em lidar com investidas físicas na procura pela } \\
\text { satisfação chegada das precisões, de modo inclusivo e, } \\
\text { principalmente, sexuais. Esses traços foram reentrantes em } \\
\text { determinados subsídios das representações, como do ponto } \\
\text { de vista em analogia à localização na folha, o tronco } \\
\text { excluído e carência de pupila nos olhares. Os fundamentais } \\
\text { efeitos autenticam as qualidades de traços típicos faladas } \\
\text { frequentemente na bibliografia e aprovam a inexistência do } \\
\text { aspecto psicológico para o agressor sexual. }\end{array}$ \\
\hline $\begin{array}{l}\text { Maria das Mercês Maia Muribec. } \\
\text { Psicopatia, violência e } \\
\text { crueldade: agressores sexuais } \\
\text { sádicos e sistemáticos. } \\
\text { Estudos de psicanálise, } 2017 .\end{array}$ & $\begin{array}{l}\text { Perceber a vontade expressa no procedimento dos atacantes } \\
\text { sexuais sádicos metódicos ou hiperviolentos não é trabalho } \\
\text { simples, principalmente quando entramos na seara dos } \\
\text { assassinatos, onde a brutalidade e a atrocidade se fazem } \\
\text { notar tão cruamente envolvidas em sua analogia com a } \\
\text { sexualidade e a morte. O conhecimento psicanalítico é } \\
\text { convidado a se ocupar do que motiva ou causa a angústia e } \\
\text { a interação das atitudesdos indivíduos, a qual é } \\
\text { sucessivamente de cunho contemplativo e particular. }\end{array}$ \\
\hline $\begin{array}{l}\text { Ana Rita Chagas Rodrigue. } \\
\text { Caracterização psicopatológica } \\
\text { dos abusadores sexuais de } \\
\text { menores intra versus extra } \\
\text { familiar. } \\
\text { Universidade Lusófona de } \\
\text { Humanidades e Tecnologias, } \\
\text { Escola de Psicologia e ciências } \\
\text { da vida, } 2017 \text {. }\end{array}$ & $\begin{array}{l}\text { Os efeitos adquiridos comprovam que os violentos sexuais } \\
\text { de menores fora da família diferenciam-se por consistir em } \\
\text { mais descontrolados cognitivamente, tiveram experiências } \\
\text { de maiores afetos contrários, tiveram uma máxima intenção } \\
\text { para o neuroticismo e por constituírem indivíduos com } \\
\text { mais sintomatologia psicopatológica comparado com } \\
\text { agressores sexuais dentro de ambientes familiares. }\end{array}$ \\
\hline
\end{tabular}

Fonte: Dados da Pesquisa

Foi alcançado como resultado deste estudo pontos relevantes, a exemplo que não necessariamente os agressores sexuais infantis sofrem com transtornos psicóticos, carência de intelectualidade e sejam menos alfabetizados do que os cidadãos da totalidade. Mas, apresentam desorganização psicológica com relação ao outro, demonstrando então serem brutos ao que diz respeito ao assunto.

Foi observado também outros fatores que dizem respeito aos ofendedores como a falta de boa vinculação com a mãe, gerando então revolta e agressividade; a busca de

Educação, Psicologia e Interfaces, Volume 3, Número 3, p. 85-100, Maio/Agosto, 2019. ISSN: 2594-5343. DOI: 
vingança pelo sentimento não saciado, punindo então o seu objeto; a sexualidade precoce e perversão nos laços afetivos, para a garantia do narcisismo; a fragmentação do que é ser bom; traumas relacionados com a vivência doméstica; significou que são muitos os fatores que levam o ser a se comportar como agressor sexual, a escolher o seu ofendido, podendo ser mensurado pelas medidas falométricas tal como o pletismógrafo peniano que incentivam o estuprador até a descoberta da sua preferência.

O perfil do agressor se desenvolve na meninice, onde o mesmo provavelmente tenha sofrido experiências de abuso de várias espécies, negligência, conflitos familiares, más experiências com relações interpessoais e pensamentos machistas influenciados pela cultura e crenças, não sendo estas pontuações incontestáveis e decisórias, mas, um arcabouço para a tal motivação. No desfecho deste trabalho os agressores foram julgados como inaptos a entender o outro, manter boas relações interpessoais, deduzir as emoções alheias e de que esses traços citados dificultem a noção de empatia e autocontrole influenciado não apenas por um fator, mas sim por vários fatores. Além disso, foi analisado a necessidade de controle e desejo pelas vítimas.

Neste estudo, os ofendedores criam a noção de que a vítima sente se atraído por eles, e alguns demonstram grande capacidade em analisar o objeto desejado e seus sentimentos, demonstrando mais uma vez a capacidade de distinguir a emoção do outro.

Diante do exposto, o analisado foi entendido como alguém que sente, mesmo que seja a atração pela escolha do agredido, isso mostra uma noção de quem seja a vítima e sua caracterização e raciocínio de quem é, fazendo então uma análise do objeto desejado.

Neste estudo foi feito uma análise dos fatores que levam o ser a torna se um agressor sexual infantil, pontuando pontos importantes da sua jornada até o ato, buscando ao máximo o entendimento do seu comportamento, pensamento sobre a ação.

De acordo com Scortegagna e Amparo (2013), a estimativa das feições de traços típicos dos agressores sexuais é um desafio na realidade do brasil., pois existe carência de estudos e de ferramentas de abalançamento. Apesar da bibliografia internacional apontar para a heterogeneidade dos atributos de personagem e psicopatológicas dos ofendedores sexuais, possuiu comprovação de algumas características psicodinâmicas, tais como problemas em dominar os impulsos e em constituir afinidades de familiaridade, traços típicos imaturos e instáveis, agressividade diante das frustações, antipatia e amorpróprio inferior. Diante desta ressalva, sugiro um maior estudo capaz de classificar a

Educação, Psicologia e Interfaces, Volume 3, Número 2, p. 85-100, Maio/Agosto, 2019. ISSN: 2594-5343. DOI: 
fundo traços da personalidade dos estudados e exames complementares que comprovem transtornos do ego dos indivíduos.

Ponderando o abuso sexual contra crianças algo muito atinado e presumindo que os abusos sexuais atentando na meninice possa ser uma morbidade de precipitação para posteriores abuso sexuais na fase crescida (Acosta \& Barker, 200; Araújo, 2008), significaria principal um ambiente psicoterápico, de caráter preventiva e/ou interventiva. Compete salientar que ofendedores juvenis necessitam, também, de cuidados e de lugares nos quais possam resinificar a ação abusivo e colocar para fora anseios, tremores e o imaginário (ARAÚJO, 2008; COSTA et al. 2011).

Chagnon (2008) nomeia como violência sexual cometida por jovens em decorrência de aprendizados educacionais inconvenientes, como aquelas fundamentadas em autoritarismo e selvageria. De outro modo, apresento o que Minuchin, Colapinto e Mincuchin (1999) descrevem como especialidades das raízes de renda rebaixada: a coordenação doméstica se volta diretamente para a sobrevivência com delegação de afazeres e encargos, e amplo direcionamento das forças para o alcance de solução financeira.

A apreciação dos fenômenos concorre com as rotinas apresentadas na bibliografia sobre a não vivência de um aspecto homogêneo e/ou atributos sociais, financeiros e de traços típicos dos ofensores sexuais (AZEVEDO, GUERRA, 2011; CHAGNON, 2011; CHAGNON, 2014; MORREL, BURTON, 2014; PASSETTI, 1999; RIVEIRA et al. 2013; SCORTEGAGNA, AMPARO, 2013). Todavia, algumas particularidades do personagem foram mais repetidas neste esboço e pedem algumas exposições. Existiu, nestas criaturas, indícios de apresentarem mais problemas em lidar com investidas corpóreas na procura pelo contentamento imediato de suas precisões, especialmente de caráter sexual, formatos infrequentes ou alteradas de entender o espaço que podem cooperar para um mau entendimento de uma circunstância, como por exemplo, ter a noção que uma criança pode conseguir avanços sexuais e se favorecer de tal relação (RYAN et al. 2008). McGlone e Viglione (2002) referem que a maior parte dos clérigos ofendedores sexuais acreditam satisfazer as necessidades emocionais da criança por meio da camaradagem sexual.

Quanto aos dados sobre os trabalhos com agressor, o escore alto está concentrado em trabalhos com adultos do gênero masculino. Tais dados corroboram o estudo de

Educação, Psicologia e Interfaces, Volume 3, Número 3, p. 85-100, Maio/Agosto, 2019. 
Williams (2012), o qual ressalta que os trabalhos cientifico sobre agressores mulheres ainda são insuficientes. Essa tese é também confirmada por Huss (2011), cujas investigações com agressores sexuais concentram- se no sexo masculino. Segundo Araújo (2008) é formidável levar em conta o assunto em que é cometido o abuso sexual por jovens, uma vez que a inclusão de pessoais poderia entusiasmar esses comportamentos. A mocidade é uma etapa de experimento e autoafirmação em afinidade sexual, de maneira que a influência do grupo de pessoais é aconselhada como um fator predisponente a pratica da ofensa sexual como forma de manifestação de virilidade para os inclusos no grupo (ARAÚJO, 2008; PRINT, MORRISON, 2002).

A dificuldade de conter impulsos e carência de intimidade e espaços de diálogo e continência afetiva nas relações familiares e sociais contribuem para a ocorrência do abuso sexual (COSTA et al. 2011). Oportunizar tais espaços e, quando possível, inserir a família do adolescente nesse processo, pode prevenir a recorrência de abuso sexual no futuro.

\section{CONSIDERAÇÕES FINAIS}

De acordo com a pesquisa feita, foi possível concluir neste trabalho que, o que impulsiona o ofendedor sexual infantil a prática do ato são as percepções e construções das experiências que ele passou desde a infância até o ato, incluindo nesta afirmativa os fatores sócios culturais entre outros meios que fizeram parte da sua formação como indivíduo. Ressaltando então que é formidável intensificar investigações do perfil psicológico e comportamental do agressor sendo ele ou ela adolescente ou adulto. Visto que a sua construção histórica não é de um ser menos intelectual que os demais não agressores da sociedade, e o seu sentimento em analogia ao ato feito para com a criança pode alterar entre múltiplas acepções.

Como também avaliação psiquiátrica de seus traços mentais, só após essa análise será possível a assimilação da personalidade do agressor e um planejamento de tratamento subjetivos, como também evitar que novos atos de agressão possam ser cometidos.

\section{REFERÊNCIAS BIBLIOGRÁFICAS}

Educação, Psicologia e Interfaces, Volume 3, Número 2, p. 85-100, Maio/Agosto, 2019. ISSN: 2594-5343. DOI: 
AMERICAN PSYCHIATRIC ASSOCIATION. Manual Diagnóstico Estatístico de Transtornos Mentais: DSM-5. Tradução: Maria Inês Corrêa Nascimento et al.; revisão técnica: Aristides Volpato Cordioli et al. 5. ed. Porto Alegre: Artmed, 2014.

ARAÚJO, S. A. Violência sexual: Sentidos atribuídos por adolescentes identificados como praticantes de abuso sexual. Trabalho apresentado no seminário Fazendo Gênero 8 - Corpo, violência e poder, Florianópolis, SC, Brasil. Disponível em: http://www.fazendogenero8.ufsc.br/sts/ST20/Suzana_Almeida_Araujo_20.pdf Acesso em: em março, 2019.

AZEVEDO, Maria Amélia; GUERRA, Viviane Nogueira de Azevedo. Pele de asno não é só história: um estudo sobre a vitimização sexual de crianças e adolescentes em família. São Paulo: Roca, 1988.

AlmeidA, F.; PAUlino, M.. Profilling, Vitimologia e Ciências Forenses Perspectivas Actuais. Lisboa: Pactor, 2002.

BECKETT, R. C. et al.. Community-based treatment for sex offenders: An evaluation of seven treatment programmes. London: Home Office Information Publications Group, Research Development Statistics Directorate, 1994.

BREWSTER, A. L.et al. Victim, perpetrator, family, and incident characteristics of 32 infant maltreatment deaths in the United States Air Force, 1998.

CARVALHO, J. Factores de Vulnerabilidade para a Agressão Sexual. Universidade de Aveiro. Departamento de Investigação, 2011.

CARVALHO, L. F; BARTHOLOMEU, D.; SILVA, M. C. R. . Instrumentos para avaliação dos transtornos da personalidade no Brasil. Avaliação Psicológica, 9(2), 289298, 2010.

CRAISSATTI, J.; MCCLURG, G.. The Challenge Project: perpetrators of child sexual abuse in South East London. Child Abuse and Neglect, 20 (11), 1067-1077, 1997. Disponível em: http://www.sciencedirect.com/science/ article/pii/0145213496000956. Acesso em; 10 jan. 2019.

CHAGNON, J-Y. . As agressões sexuais: uma organização de transtornos narcísicoidentitários. Paidéia, 18(41), 495-515, 2008.

GENEVIÈVE, M.; TARDIF, M. What we do and don't know about sex offenders intimacy. Aggression and Violent Behavior. Vol 19 (4), pp. 372-382, 2014.

GUARESCHI, Neuza M. F. et al. Discussões sobre violência: trabalhando a produção de sentidos. Psicologia: Reflexão e Crítica, v. 19, n. 1, p. 122-130, 2006.

CHAGNON, J.Y. As agressões sexuais: uma organização de transtornos narcísicoidentitários. Paidéia, 18(41), 495-515, 2008.

FERRARI, Dalka Chaves Almeida; VECINA, Tereza Cristina Cruz (Orgs.). O fim do silêncio na violência familiar: teoria e prática. São Paulo: Ágora, 2002.

Educação, Psicologia e Interfaces, Volume 3, Número 3, p. 85-100, Maio/Agosto, 2019.

ISSN: 2594-5343. DOI: 
GACONO, C. B.; MELOY, J. R.; BRIDGES, M. R.. A Rorschach understanding of psychopaths, sexual homicide perpetrators, and nonviolent pedophiles. In: Gacono, C. B. et al.. The Handbook of Forensic Rorschach Assessment. New York: Routledge, 2011.

GOMES, R.; et al. Por que as crianças são maltratadas? Explicações para a prática de maus-tratos infantis na literatura. Cadernos de saúde pública, Rio de Janeiro, v. 18, n. 3, 2002. Disponível em: \&lt;http://www.scielo.br/pdf/csp/v18n3/9298.pdf\&gt Acesso em: 23 jan. 2015.

LANNING, K.V. Ritual abuse: a law enforcement view or perspective. Child Abuse Negl, 15(3):171-3, 1991.

MARQUES, Heloisa M. de V. A voz do abusador: aspectos psicológicos dos protagonistas de incesto. Dissertação de Mestrado, Programa de Pós-Graduação em Psicologia, Universidade Católica de Brasília, Brasília, 2005. Disponível em: <http://www.bdtd.ucb.br/tede/tde_busca/arquivo.php?codArquivo=648> Acesso em: 04 de maio de 2018.

MARSHALL, W. L. . Agresores sexuales. Barcelona: Ariel, 2001.

MELOY, J. R.; GACONO, C. B.; KENNEY, L.. A Rorschach investigation of sexual homicide. Journal of Personality Assessment, 62(1), 58-67, 1994.

MOURA, A. S; KOLLER, S. H. A criança na visão de homens acusados de abuso sexual: um estudo sobre distorções cognitivas. Psico- USF, Rio Grande do Sul, v. 13, n.1, 2008. Disponível em: <http://www.scielo.br/pdf/pusf/v13n1/v13n1a11.pdf>. Acesso em 10 mai. 2018.

QUINSEY, V.; LALUMIÈRE, M.. Assessment of sexual offenders against Children. 2 ed. Thousand Oaks, California: Sage Publications, Inc. 2001.

SAMPAIO, R.F.; MACINI, M.C. . Estudos de revisão sistemática: um guia para síntese criteriosa de evidência científica. Revista Brasileira de Fisioterapia, 11 (1,), P.83-89. 2007. Disponível em: http:// www. Scielo.br/ pdf/rbfis/v11n1/12.pdf. Acesso em 10 mai. 2018.

SANDERSON, Cristiane. Abuso sexual em crianças: fortalecendo pais e professores para proteger crianças de abusos sexuais. São Paulo: M. Books do Brasil, 2005.

SALTER, Anna C. Predadores - Pedófilos, Estupradores e Outros Agressores Sexuais. São Paulo: M. Books do Brasil, 2009.

SEIDMAN, B. T. et al. An Examination of Intimacy and Loneliness in Sex Offenders. J Interpers Violence, 9; 518- 534, 1994.

SERAFIM, A. P. et al. Perfil psicológico e comportamental de agressores sexuais de crianças. Rev Psiq Clín., 36(3), pp.105-11, 2009.

Educação, Psicologia e Interfaces, Volume 3, Número 2, p. 85-100, Maio/Agosto, 2019. ISSN: 2594-5343. DOI: 
TELES, V. M. C. Bissexualidade: identidade, identificações e comportamento sexual - um estudo de casos. 1999. 92 f. Dissertação de Mestrado em Psicologia Social, Cognitiva e da Personalidade, Universidade Federal do Rio de Janeiro - Instituto de Psicologia, Rio de Janeiro, 1999.

VIEIRA, S. . Ofensores sexuais: das crenças ao estilo de pensamento. Tese de Doutoramento em Psicologia. Universidade do Minho, 2011.

\section{Credenciais da/os autora/es}

SANTOS, Alaniane Souza Freire. Centro Universitário Maurício de Nassau /Brasil. Email: alanianepsi@gmail.com

MESQUISTA, Ana Catarina Correia. Professora no Centro Universitário Maurício de Nassau /Brasil. specialista em Gestão Estratégica de Pessoas pela Universidade Federal do Piauí. E-mail: anacatarinacorreia@ @otmail.com

Endereço para correspondência: Alaniane Souza Freire Santos. E-mail:

alanianepsi@gmail.com

Como citar este artigo (Formato ABNT): SANTOS, Alaniane Souza Freire; MESQUISTA, Ana Catarina Correia. O perfil do agressor sexual infantil: uma revisão bibliográfica. Educação, Psicologia e Interfaces, v. 3, n.3, p. 85-100, 2019.

Recebido: 07/05/2019.

Aceito: 20/06/2019. 